$2020,21(4)$, pp. 514-524, DOI: 10.18038/estubtda. 632877

RESEARCH ARTICLE

\title{
ASSESSING SOUND-MUFFLING CHARACTERISTICS OF FLY-ASH NANO-PARTICLE REINFORCED EPOXY RESIN COMPOSITES
}

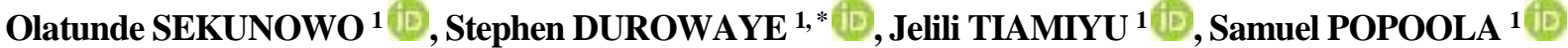 \\ ${ }^{1}$ Department of Metallurgical and Materials Engineering, Faculty of Engineering, University of Lagos, Nigeria.
}

\begin{abstract}
Effective reduction and control of noise have continued to attract attention globally due to the adverse effects noise poses to human health, effective knowledge dissemination and desirable environmental tranquility. The use of natural and synthetic reinforced composites in noise pollution control is an emerging area of research. In this study, coal fly-ash in nanoparticles varied at 5-25 wt. \% was employed as reinforcement in the fabrication of epoxy resin composites. The composites were characterized both for noise reduction capability and mechanical properties necessary for a damage-free handling during installation. Results showed that samples of the composites at $15 \mathrm{wt}$. \% exhibited the highest noise reduction coefficient (NRC) of 0.8072 . This translates to $81 \%$ noise reduction capability if deployed in a facility and compares very well with that of conventional acoustical materials that are used in buildings and other facilities. The mechanical properties exhibited by the composite samples in terms of flexural strength (20.3 - 43.7 MPa), impact energy (4.4 - 4.8 J), and hardness $(13.3-15.3 \mathrm{HV})$ are sufficient for the intended area of application. Thus, the composite developed at $15 \mathrm{wt} \%$ fly-ash addition is recommended for deployment in auditorium (lecture theatre), public library, hospital ward and hotels. These facilities have maximum recommended noise levels in the range of $35-45 \mathrm{db}$. The composites are adjudged suitable for application as noise muffling materials in buildings and other facilities that are usually subjected to low mechanical system noise sources.
\end{abstract}

Keywords: Noise pollution, Noise reduction coefficient, Polymer matrix composite, Fly-ash nanoparticles, Mechanical properties

\section{INTRODUCTION}

Noise being an unwanted sound is a serious social malaise that plague every segment of societies worldwide. It is established that normal sound frequency range for human hearing is $20 \mathrm{~Hz}-20 \mathrm{kHz}$ [1]. However, on daily basis people are subjected to noise frequency range between $50 \mathrm{~Hz}$ and $50 \mathrm{kHz}$ corresponding to a rather uncomfortable noise level greater than 80 decibels. This underscores the continuous quality attention being placed on how best to reduce significantly the generation and transmission of unwanted sound [2]. Effective noise reduction and control lie in understanding the mechanism by which noise is transmitted. According to [3], the science of hearing sound in spaces can be broadly divided into three stages namely; sound production, sound reproduction and noise control.

Noise control has become an important part of architectural design due to its high probability to harm human well-being causing disruption of normal sleep pattern, hearing impairment, loss of concentration and other debilitating effects. Recent discoveries established that constant exposure to noises can cause both auditory and non-auditory health problems such as cardio-vascular diseases, sleep disturbance and annoyance $[4,5]$. Thus, the main goal of most architectural design modification of buildings and structures is to reduce or eliminate the noise power, either outdoors or indoors [6]. Furthermore, the understanding of the nature of sound as a wave which propagates through physical mediums such as air is imperative for effective curtailment [7]. Eventual propagation of sound involves three contiguous processes namely; transmission, absorption and reflection. However, the amount of energy going into transmission, absorption or reflection depends on the surface's acoustic properties. Thus, the sound that is heard is usually a combination of direct sound straight from the source and indirect reflections from surfaces and other objects in the environments. Hence, sound can be controlled either from the source (active control) or from the surroundings (passive control). In real life situations both passive and active sound control is essential in order to perceive the right sound.

*Corresponding Author: durosteve02@yahoo.com

Received: 14.10.2019 Published: 28.12.2020 
Currently, the common in-door sound muffling materials in use are polymers and ceramics. However, polymers such as vinyl ester, epoxy, and polyurethane in which pores have been induced during processing are most preferred $[8,9]$. Epoxy resins are thermosets often used in polymer matrix composites due to their good resistance to chemical attack, lightweight and excellent insulating properties [10]. In order to prevent polymer matrix composites from mechanical damage, they are usually reinforced by either organic or inorganic fillers such as certain industrial wastes including coal fly-ash, carbon black, or processed agricultural waste such as rice husk-ash [11, 12]. Fly-ash is a coal combustion byproduct constituting a major environment problem. It consists of silt-sized spherical particles oxides of silicon, aluminum, calcium, magnesium and other metallic oxides in trace amounts [13]. The unique spherical shape and particle distribution of fly-ash makes it a good filler material in polymer matrix composites. According to [14], the average coal fly-ash annual production worldwide is put at 700 million tons.

In view of the foregoing, the development and deployment of sound absorber materials appear to be the panacea to the pervasive noise pollution in our environments $[15,16]$. The aim of this study is to develop and characterize fly-ash nanoparticles reinforced polymer composites suitable for noise reduction purposes.

\section{MATERIALS AND METHODS}

\subsection{Materials and Equipment}

The major materials used in this study include epoxy resin/hardener sourced commercially and coal flyash obtained from Lafarge Cement Manufacturing Company, Ewekoro, Ogun state, Nigeria. The equipment used for both the composites synthesis and characterization include a ball-mill, mechanical stirrer, FTIR and XRF analyzers to validate the type of epoxy resin used and the fly-ash composition respectively. An impedance tube was used to generate noise parameters data from which the Noise Reduction Coefficients (NRC) of the composites were computed. The mechanical characterization of the composites was carried out using Instron mechanical tester, Avery impact tester and Vickers hardness tester while an optical microscope was used for the microstructural examination.

\subsection{Composites Production}

Powder metallurgy technique was employed in the production of the composites. The coal fly-ash was milled using a steel ball mill (model A50 43, Mashine, France) and sieved to nanoparticle size using British standardized sieves (BSS). This procedure agrees with the method adopted by [17, 18] concerning ball milling of carbonised organic particles. Sustainability of the procedure is ensured by producing the nanosized fly-ash particles in bulk prior to the commencement of the composite production. Thereafter, fly-ash nano particles production continues simultaneously with the composite production. Then mechanical mixing of the reinforcement with the epoxy resin was carried out according to calculated materials formulation shown in Table 1. Each formulation of the composite weighs $60 \mathrm{~g}$ and the mixture was stirred vigorously to achieve homogeneous blend and as well exclude air bubbles. The mixture was then poured into prepared wooden molds coated with paper tape which served as the mold releasing agent. This was followed by casting of the composites which were allowed to cure at room temperature for 24 hours and then stripped for characterizations.

Table 1. Materials formulation

\begin{tabular}{|c|c|c|c|c|c|c|}
\hline \multirow[t]{2}{*}{ Sample } & \multicolumn{4}{|c|}{ Matrix } & \multicolumn{2}{|c|}{ Reinforcement } \\
\hline & $\begin{array}{c}\text { Epoxy resin } \\
(\mathrm{g})\end{array}$ & $\begin{array}{c}\text { Epoxy resin, } \\
\text { wt. } \%\end{array}$ & $\begin{array}{l}\text { Hardener } \\
(\mathrm{g})\end{array}$ & $\begin{array}{c}\text { Hardener wt. } \\
\%\end{array}$ & $\begin{array}{c}\text { Fly-ash } \\
\text { nanoparticles (g) }\end{array}$ & $\begin{array}{c}\text { Fly-ash } \\
\text { nanoparticles, wt. } \\
\%\end{array}$ \\
\hline $\mathbf{A}$ & 40 & 67 & 20 & 33 & 0 & 0 \\
\hline B & 38 & 63 & 19 & 32 & 3 & 5 \\
\hline $\mathbf{C}$ & 36 & 60 & 18 & 30 & 6 & 10 \\
\hline D & 34 & 57 & 17 & 28 & 12 & 15 \\
\hline $\mathbf{E}$ & 32 & 53 & 16 & 27 & 15 & 20 \\
\hline $\mathbf{F}$ & 30 & 50 & 15 & 25 & 18 & 25 \\
\hline
\end{tabular}




\subsection{Sound Absorption Test}

The sound absorption tests were carried out in department of Physics laboratory, University of Jos, Nigeria using the Transfer Function Method (TFM). This test method makes use of an Impedance tube configured with a digital frequency analyzer for the determination of sound absorption coefficient as shown in Figures 1 and 2.

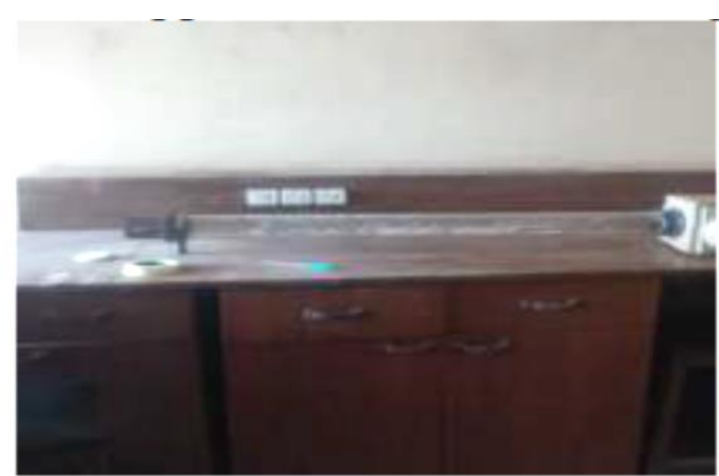

Figure 1. Impedance tube

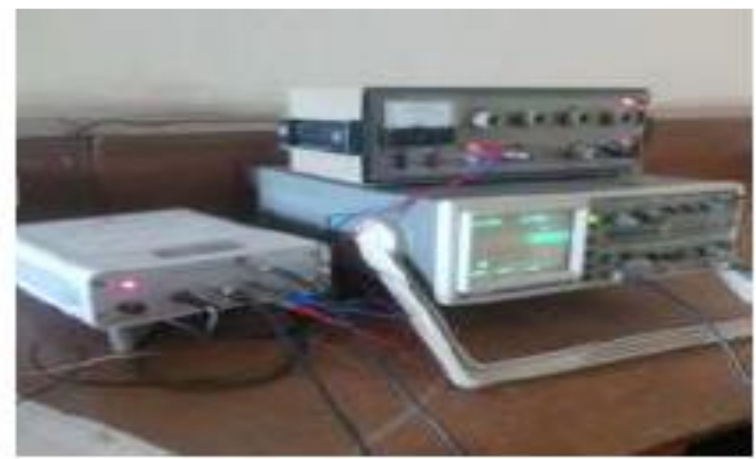

Figure 2. Frequency analyser

The experimental procedure involves five (5) successive steps namely: (i) test sample was fitted to the sample holder and into the impedance while the signal generator was adjusted to give a frequency of $1000 \mathrm{~Hz}$ sound wave. Furthermore, the Cathode Ray Oscilloscope (CRO) was adjusted to show the function generator output; (ii) the signal generator output was moved to leave the CRO screen to clear the way for the microphone signal; (iii) the microphone was moved along the axis of the impedance tube until the amplitude of the trace on the CRO is at a minimum while the peak to peak height of the trace was recorded as $\mathrm{V}_{2}$; (iv) the microphone was further moved until the amplitude of the trace was at a maximum and the peak to peak values recorded as $\mathrm{V}_{1}$ and (v) the frequency was changed to $2 \mathrm{KHz}, 3$ $\mathrm{KHz}, 4 \mathrm{KHz}, 5 \mathrm{KHz}$ and $6 \mathrm{KHz}$ respectively while procedures i-iv were repeated for each frequency.

\subsection{Mechanical Test}

Three-point flexural test was conducted on the composite samples of dimension $12 \times 5 \times 0.5 \mathrm{~cm}$ at room temperature using an Instron electromechanical testing machine according to ASTM D7264 standard. The experiment was conducted under a crosshead speed of $30 \mathrm{~mm} / \mathrm{min}$ maintained at a span of $100 \mathrm{~mm}$. An Avery impact testing machine was used to evaluate the impact toughness of the samples dimensioned to $5 \times 1.5 \times 0.5 \mathrm{~cm}$ in accordance with ASTM E23 standard. The Vickers hardness values of the composite samples of dimension $4.4 \times 4.4 \times 0.5 \mathrm{~cm}$ were obtained using a micro-hardness tester.

\section{RESULTS AND DISCUSSION}

\subsection{Chemical Composition}

The XRF analysis results carried out on the fly-ash nanoparticles (FLA $\left.{ }_{\mathrm{NP}}\right)$ is presented in Table 2.

Table 2. Composition of fly-ash

\begin{tabular}{lccccccccccc}
\hline Composition & $\mathrm{SiO}_{2}$ & $\mathrm{Al}_{2} \mathrm{O}_{3}$ & $\mathrm{Fe}_{2} \mathrm{O}_{3}$ & $\mathrm{~K}_{2} \mathrm{O}$ & $\mathbf{C a O}$ & $\mathrm{MgO}$ & $\mathrm{P}_{2} \mathrm{O}_{5}$ & $\mathrm{TiO}_{2}$ & $\mathrm{Na}_{2} \mathrm{O}$ & $\mathrm{SO}_{3}$ & ${ }^{*} \mathrm{L.O.I}$ \\
\hline Wt. \% & 50.23 & 25.85 & 6.31 & 3.84 & 3.22 & 2.00 & 1.39 & 1.17 & 1.20 & 0.09 & 4.70 \\
\hline
\end{tabular}

*Loss on Ignition

The result in Table 2 shows that fly-ash consist of relatively high silicate glass known as cenospheres followed by $\mathrm{Al}_{2} \mathrm{O}_{3}, \mathrm{Fe}_{2} \mathrm{O}_{3}, \mathrm{~K}_{2} \mathrm{O}, \mathrm{CaO}, \mathrm{MgO}, \mathrm{P}_{2} \mathrm{O}_{5}, \mathrm{TiO}_{2}, \mathrm{Na}_{2} \mathrm{O}, \mathrm{SO}_{3}$. According to [13], cenospheres consist of silicate glass in which the silica content is higher than the calcium content. The main application of cenospheres is as inert fillers, in which they often provide up to four times the bulk filler 
capacity. Furthermore, being inert, they are resistant to most acids and high temperature conditions. Thus, cenospheres can be used in plastics, glass-reinforced plastics, light-weight panels, refractory tiles and almost anywhere that traditional fillers can be used [19].

\subsection{Fourier Transform Infrared (FTIR) Spectroscopy}

The FTIR result presentes in Figure 3 shows that the epoxy rein used is Diglycidyl ether of bisphenolA (DGEBA). Although, the spectra look similar to its hydrogenated derivative (HDGEBA), but the differences become obvious from the difference in peak values coupled with the absence of aromatic rings in HDGEBA. These features usually influence epoxy resin functional properties such as the glass transition temperature, viscosity and reaction rate [20]. The highest peak of the epoxy resin observed at $1510.31 \mathrm{~cm}^{-1}$ is within the carbonyl region $\left(1500-1700 \mathrm{~cm}^{-1}\right)$. This is common for epoxy resin as they show prominent $\mathrm{C}=\mathrm{O}$ peaks in this region. These days the use of epoxy resin in natural fiber based composites is gaining prominence owing to its low weight, ease of synthesis and competitive cost. Furthermore, epoxy in natural fiber based composites have been found to confer excellent sound attenuation characteristics coupled with environmental friendliness and minimal impact on human health [21]. Hence, researchers [22, 23] are proposing its usage as a viable replacement for glass-fiber composites especially in applications where sound absorption is important.

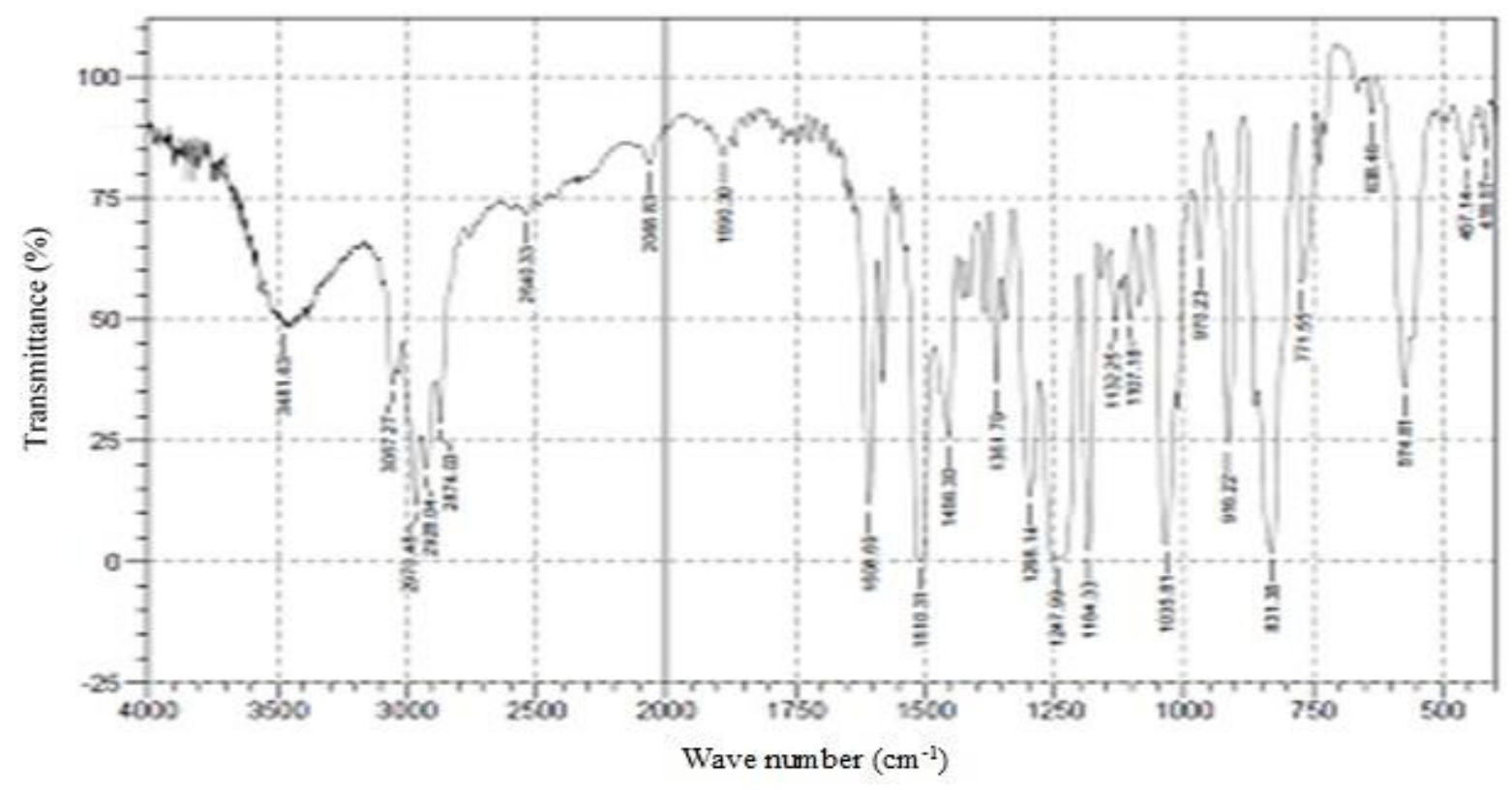

\subsection{Microstructure}

Figure 3. FTIR of the as-received epoxy resin

The optical micrographs of the composites at varied FLA $\mathrm{NP}_{\mathrm{N}}$ addition are shown in Figure $4 \mathrm{~b}-4 \mathrm{f}$. Addition of FLA $\mathrm{NP}_{\mathrm{NP}}$ influenced the microstructural features to the extent of fractions of pores dispersed homogeneously within the epoxy resin matrix. However, the control sample's micrograph without filler


seen dispersed evenly within the matrices (Figure $4 b-4 f$ ). The pores in Figure $4 \mathrm{~b}$ appear isolated while the pores in Figure $4 \mathrm{c}$ and Figure 4d developed into a network in a peculiar textural pattern as FLA addition increased from $10 \mathrm{wt}$. \% to $15 \mathrm{wt}$. \%. Further increase in FLA $\mathrm{A}_{\mathrm{NP}}$ addition at $20-25 \mathrm{wt}$. \%, the matrices (Figures 4e and 4f) appear saturated and the fillers completely subsumed in the epoxy resin. Formation of pores may have stemmed from the combination of vacuum created during cross-linking and condensed moisture due to the hydrophobic nature of epoxy resin. The dynamics of sound impact on a material can be liken to the process of wave generation and propagation. The mechanism by which such wave is absolved and reflected depends on the material structure such that continuity in structure ensures thorough passage of the wave through the material [3,6]. However, the presence of vacuum 
within the material favors a situation where significant portion of the wave is absorbed. In this study, the presence of pores developed in the material as shown in the micrographs serve as sound waves sink. The preponderance of inter connected pores in the composites further enhances the attenuation capability of the composites. In particular, Figure $4 \mathrm{~d}$ shows significant presence of inter connected pores that may enhance its sound absorption ability.



(a)



(c)

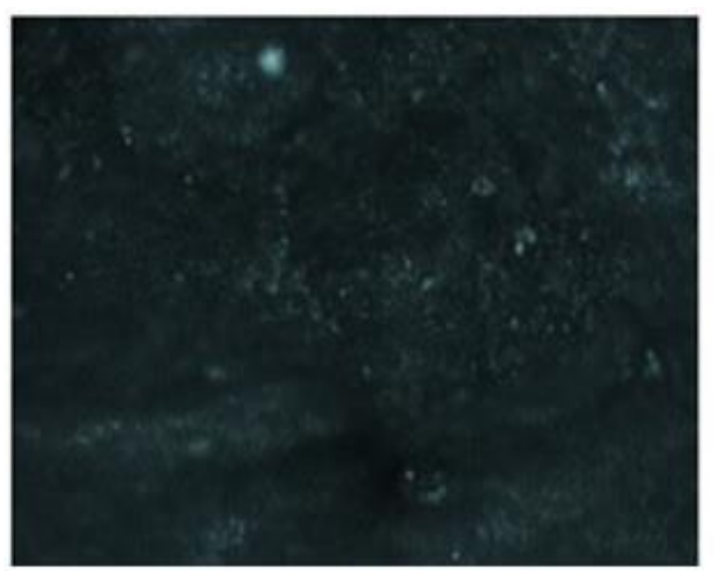

(e)

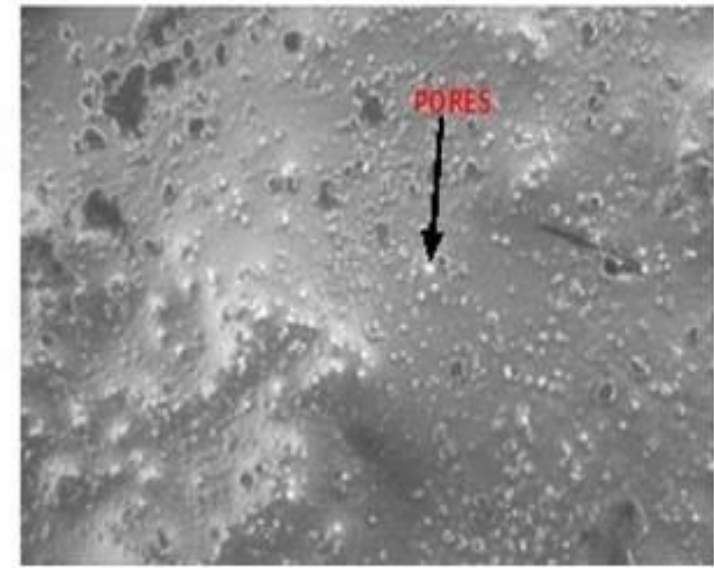

(b)

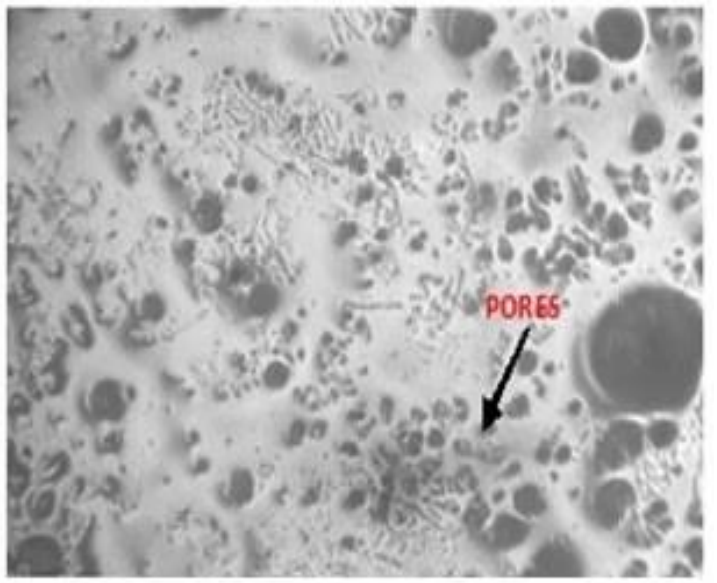

(d)

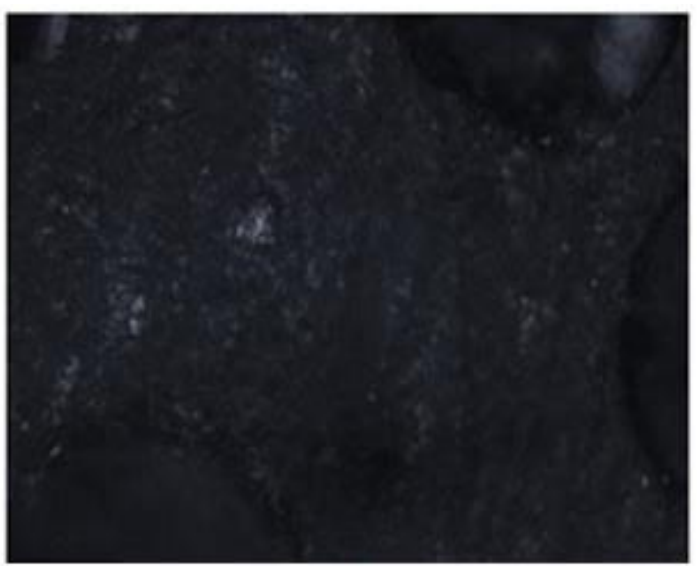

(f)

Figure 4. Optical micrographs at varied fly-ash addition (a) 0 wt.\% FLA NP , (b) 5 wt.\%, FLA (d) 15 wt.\% FLA FP , (e) 25 wt. $\%$ FLA $_{\mathrm{NP}}$, (f) 25 wt.\% FLA $\mathrm{FP}_{\mathrm{NP}} \mathrm{x} 200$ 


\subsection{Sound Absorption Response}

The sound absorption response of the fly-ash nanoparticles reinforced epoxy resin at varied sound frequencies from $1-6 \mathrm{kHz}$ is presented in Table 3 .

Table 3. Sound absorption coefficient (SAC)

\begin{tabular}{ccccccc}
\hline Frequency $(\mathbf{k H z})$ & \multicolumn{6}{c}{ SOUND ABSORPTION COEFFICIENT $(\boldsymbol{\alpha})$} \\
\cline { 2 - 7 } $\mathbf{1}$ & $\mathrm{A}$ & $\mathrm{B}$ & $\mathrm{C}$ & $\mathrm{D}$ & $\mathrm{E}$ & $\mathrm{F}$ \\
$\mathbf{2}$ & 0.8889 & 0.8889 & 0.5925 & 0.8594 & 0.1519 & 0.1814 \\
$\mathbf{3}$ & 0.4898 & 0.2602 & 0.6567 & 0.6980 & 0.1249 & 0.7601 \\
$\mathbf{4}$ & 0.8889 & 0.8741 & 0.9902 & 0.5017 & 0.9722 & 0.5707 \\
$\mathbf{5}$ & 0.7500 & 0.8889 & 0.8405 & 0.9711 & 0.2215 & 0.4375 \\
$\mathbf{6}$ & 0.6036 & 0.8568 & 0.8741 & 0.8889 & 0.3803 & 0.5556 \\
& 0.6400 & 0.9467 & 0.8889 & 0.8889 & 0.9902 & 0.1814 \\
\hline
\end{tabular}

The SAC values in Table 3 indicate the sound absorbing properties of fly-ash reinforced epoxy resin at different frequency. Computation of SAC data for application is rather cumbersome and not easily comprehensible. Hence, for application purposes, Noise Reduction Coefficient (NRC) is usually adopted as expressed in using equation (1) [24].

$$
\mathrm{NRC}=\frac{(\alpha 1+\alpha 2+\alpha 3+\alpha 4+\alpha 5+\alpha 6) \mathrm{kHz}}{6}
$$

Where: $\alpha_{\mathrm{n}}=$ Sound absorption coefficients at $1 \mathrm{kHz}, 2 \mathrm{kHz}, 3 \mathrm{kHz}, 4 \mathrm{kHz}, 5 \mathrm{kHz}$, and $6 \mathrm{kHz}$.

Substituting SAC values in equation (1) for each sample formulation yields the NRC values of 0.7102 , $0.7859,0.8072,0.4735$ and 0.4478 respectively for samples A, B, C, D, E and F.

The sound muffling capacity of the composites as illustrated in Figure 5 correlates the microstructural features in terms of the nature and dispersion of pores formed. NRC measures how well materials stop sound from reflecting (how much sound they can absorb). The NRC is the percentage of sound that a surface absorbs (in other words, hits a surface and does not reflect back again into the room). A material is usually considered to be a sound absorber if it has an NRC value greater than 0.35 [25]. To be an effective sound absorber, a material must have interconnecting air pockets or pores [25].

Hence, pores in this case serve as sound sink where sound in the form of vibration incident on the composites is significantly absorbed releasing just a fraction at low decibels between $35 \mathrm{db}$ and $45 \mathrm{db}$. The effectiveness of the pores sound muffling capacity is dependent on their interconnectivity [3]. This accounts for the peak performance of samples C and D (10 and 15 wt. \% FLA $\left.A_{N P}\right)$ which exhibited the highest NRC value of 0.8072 . Materials sound absorption capability depends on acoustic impedance of the media which is a function of the frequency [11]. In this case, frequency approximates different sources of sound including mechanical vibration such as from air-conditioner, washing machine, electric generator all accommodated in a building. From Table 3, it is observed that at a relatively highfrequencies; $4-6 \mathrm{kHz}$ the SACs are in the range of $0.89-0.97$. This means that efficiency of the composites is ensured when the sound source synchronizes with the acoustic panel capacity. Sustained elevated sound absorption above 80 decibels is known to be injurious to human health sometimes resulting in hearing damage. However, from the results in Table 3 , the optimum mixture containg 15 wt. \% fly-ash exhibited such NRC (0.807) that appears sufficient for desirable sound muffling need in facilities such as hospital wards, conference halls, public library, etc. Generally, noise levels in these facilities which are in the range of 70-120 db can be muffled down to as low as 35-45 db by deploying the optimum mixture composite panel. Other acoustic materials that exhibit comparable performances include acoustic tile (0.9), carpet over concrete (0.72), $25 \mathrm{~mm}$ fiberglass board (0.98), etc. 
The NRC value (0.8072) of sampes C and D compared very well with that of conventional acoustical materials that are used in buildings and other facilities presented in Table 4. Samples C and D must have possessed a relatively high volume fraction of inter connected pores compared to sample A with predominantly isolated pores. The sound muffling ability of the composites at $20-25$ wt. \% fly-ash nanoparticles addition was impaired due to the absence of functional pores as the matrices were completely saturated with the filler.

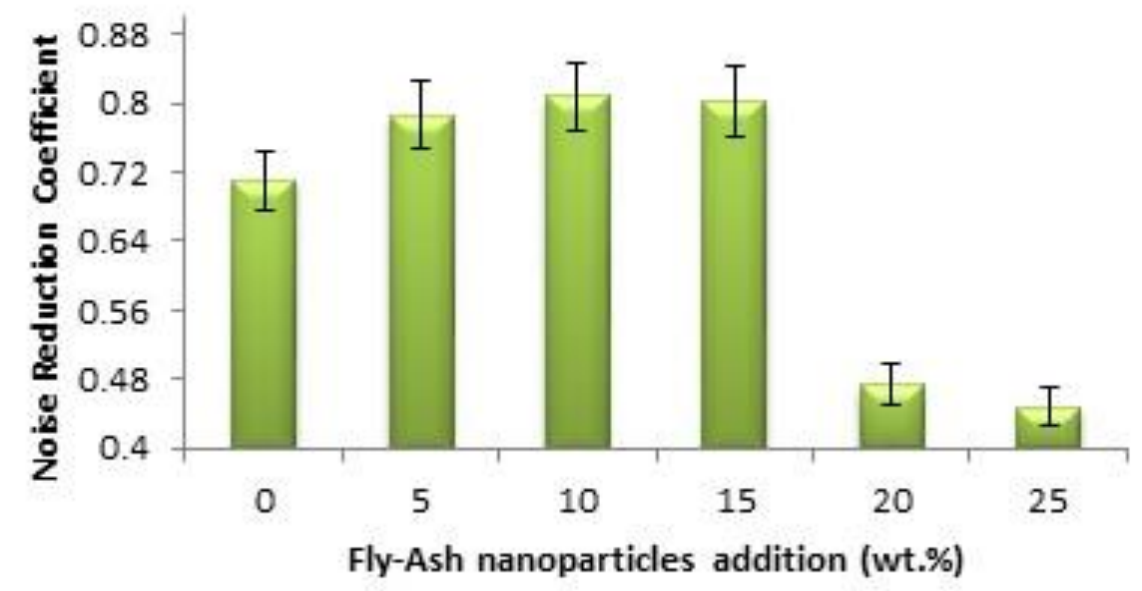

Figure 5. Noise reduction coefficient (NRC) of epoxy resin at varied fly-ash addition

Table 4. Noise reduction coefficient of conventional acoustical materials [25]

\begin{tabular}{cc}
\hline Materials & NRC \\
\hline Brick (unglazed) & 0.05 \\
Concrete block (unpainted) & 0.05 \\
Carpet (combined pile and foam) & 0.35 \\
Fabric (heavy velour) & 0.60 \\
Fabric (medium velour) & 0.55 \\
Floors (concrete) & 0.05 \\
Floors (wood) & 0.10 \\
Glass & 0.05 \\
Gypsum board & 0.05 \\
Marble or glazed tile & 0.00 \\
Plaster (gypsum or lime) & 0.05 \\
Plywood paneling & 0.10 \\
Wood roof decking & 0.15 \\
Commercial board (CB) unfaced 150 & $0.80-1.00$ \\
Commercial board (CB) unfaced 225 & $0.70-1.05$ \\
Commercial board (CB) unfaced 300 & $0.70-1.05$ \\
Commercial board (CB) unfaced 600 & $0.75-1.00$ \\
Black acousta board (TYPE 225) & $0.65-0.95$ \\
Black acousta board (TYPE 300) & $0.70-0.95$ \\
\hline
\end{tabular}

\subsection{Flexural Strength}

The flexural property of the composites at varied filler addition is depicted in Figure 6. This is the measure of the composites ability to withstand unrecoverable warpage or fracture under bending load. The control sample (unreinforced epoxy resin) exhibited the highest flexural strength of $56.1 \mathrm{MPa}$ which decreased monotonously as fly-ash nanoparticles increased from $5-25$ wt. \% corresponding to 43.7 20.3 MPa. This behavior agrees with [26,27] which is attributted to bending stiffness often resulting in limited plastic deformation with a tendency for brittle fracture. The pattern of flexural strength performance by the reinforced samples is attributed to the quasi discontinuity in structure occasioned by 
pore formation. This gave rise to a rather poor load transfer between the reinforcing phase and matrix thereby causing concomitant decrease in flexural strength commensurate to the increase in fly-ash wt. $\%$ addition. Considering the report by $[28,29]$, the range of flexural strength $(43.1-33.9 \mathrm{MPa})$ demonstrated by the composite samples at $5-15 \mathrm{wt}$. \% fly-ash addition is adjudged sufficient for both damage-free installation and durability in service of the panels.

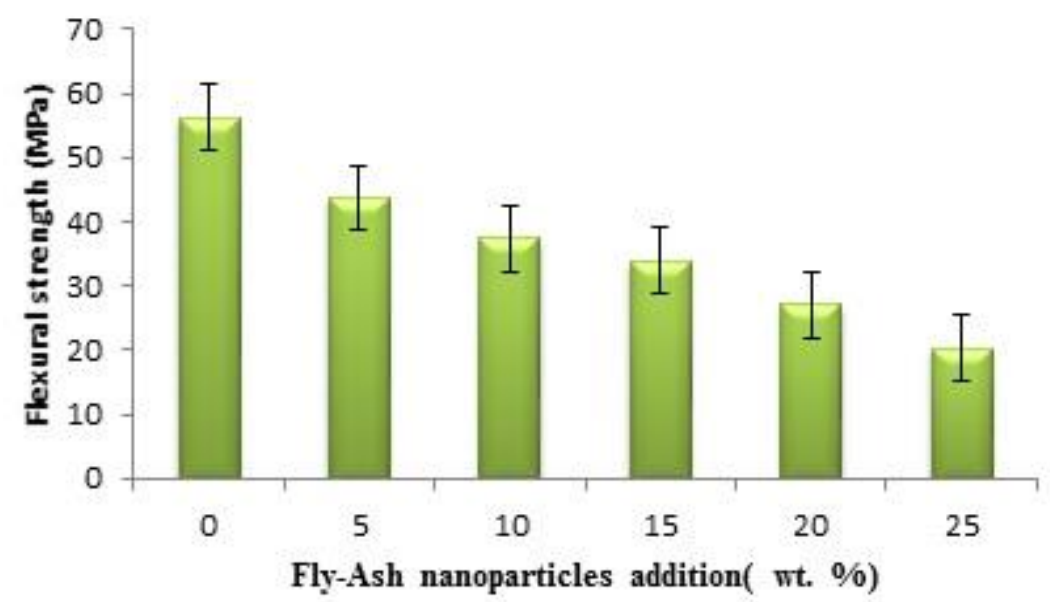

Figure 6. Flexural strength of epoxy resin at varied fly-ash addition

\subsection{Impact Energy}

The impact energy of the unreinforced epoxy resin is relatively high, $3.6 \mathrm{~J}$ but failed to measure up to dynamic stability at varied fly-ash addition as shown in Figure 7. However, the highest impact energy of $4.8 \mathrm{~J}$ was exhibited at $5 \mathrm{wt}$. \% fly ash addition. This may be attributted to moisture induced within the matrix during synthesis, epoxy resin being hydrophobic in nature. According to [30], moisture absorption has a deleterious effect on Charpy impact toughness of polymer matrix composites. At 5 15 wt. \% fly-ash addition, impact energy range from $4.8-4.4 \mathrm{~J}$ which is adjudged sufficient for the intended area of application. However, the relatively low impact performance of the composites may be attributed to impaired strength of cross-linked chains arising from pores induced discontinuity in the structure.

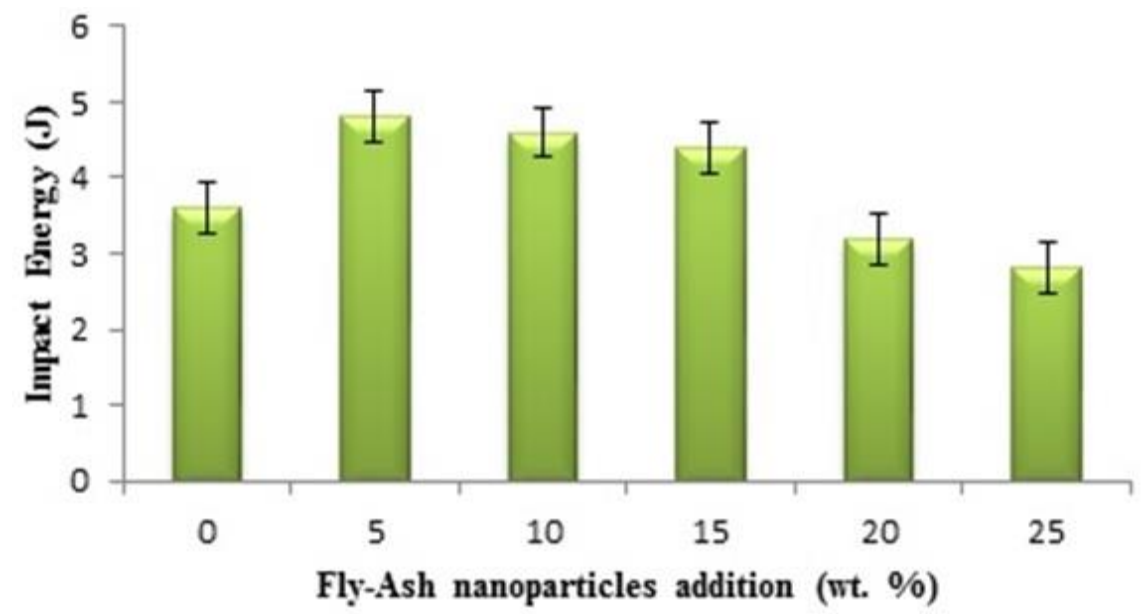

Figure 7. Impact energy of epoxy resin at varied fly-ash addition 


\subsection{Hardness}

The surface resistance to damage demonstrated by the composites was evaluated through Vickers hardness technique and the result is illustrated in Figure 8. Due to the microstructural features induced in the composites on fly-ash nanoparticles addition (Figure 4b - 4f), a modest level of hardness, 25.4 $19.5 \mathrm{HV}$ was exhibited at $5-15$ wt. \%. However, a highest hardness value of $25.4 \mathrm{HV}$ was exhibited at 5 wt. \% fly ash addition. Decrease in hardness in the range of $15.3-13.3 \mathrm{HV}$ at $20-25$ wt. \% addition could be due to de-bonding phenomenon between the matrix and the reinforcing phase sequel to the impairment of epoxy resin cross-linking cohesion [31]. The relatively high hardness value $(25.4 \mathrm{HV})$ demonstrated by the $15 \mathrm{wt}$ \% fly-ash nanoparticles mixture was enabled by the intrinsic high hardness of nano particles which provided resistance to the movement of epoxy resin chain on application of load on it. This agrees with [32] as reported in the case of polymer matrix composite reinforced wit nano silica particles and glass fibers.

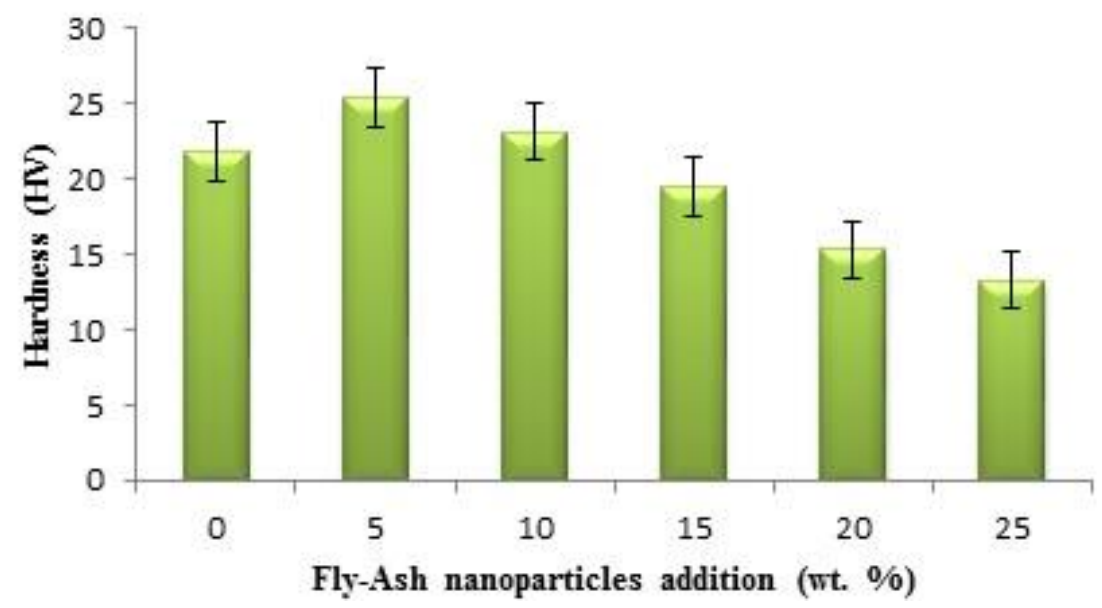

Figure 8. Hardness of epoxy resin at varied fly-ash addition

\section{CONCLUSION}

Assessment of the noise level abatement capacity of synthesized fly-ash nanoparticles reinforced epoxy resin composites has been successfully carried out. Relevant mechanical properties necessary for damage-free installation were also investigated. The inducement of inter-connected pores in the composites at 10 and $15 \mathrm{wt}$ \% fly-ash addition gave rise to desirable Noise Reduction Coefficient (NRC) value of 0.8072 . The NRC value (0.8072) of sampes C and D compared very well with that of conventional acoustical materials that are used in buildings and other facilities presented in Table 4 which may be vulnerable to noise pollution. Samples C and D must have possessed a relatively higher volume fraction of inter connected pores compared to other samples which facilitated enhanced NRC. The mechanical properties exhibited by the composite samples in terms of flexural strength $(20.3-43.7$ $\mathrm{MPa})$, impact energy $(4.4-4.8 \mathrm{~J})$, and hardness $(13.3-15.3 \mathrm{HV})$ are appreciable and considered to be sufficient for safe handling and durable for the intended areas of application.

\section{REFERENCES}

[1] Harris C. Human Response to Sound. Handbook of Acoustical Measurement and Noise Control. $3^{\text {rd }}$ Edition, McGraw-Hill, 1991.

[2] Ogunbowale WO, Banks-lee P, Bello KA, Maiwada S, Kolawole EG. Acoustical absorptive properties of cotton, polylactic acid batts and fabrics. American International Journal of Contemporary Research 2012; 2(11): 9-19. 
Sekunowo et al. / Eskişehir Technical Univ. J. of Sci. and Tech. A - Appl. Sci. and Eng. 21(4) - 2020

[3] Cox TJ, D'antonio P. Acoustic absorbers and diffusers: theory, design and application. CRC Press, $2^{\text {nd }}$ Edition. USA. 2004.

[4] Basner M, Charlotte C, Anna H, Sparrow V. Aviation noise 1mpacts: state of the science. Noise and Health 2014; 19(87): 41-50.

[5] Peng L, Song B, Wang J, Wang D. Mechanic and acoustic properties of the sound-absorbing material made from natural fiber and polyester. Advances in Materials Science and Engineering 2015; 4: $1-5$.

[6] Paulo HT, Fernanda F. Assessment of indoor and outdoor noise pollution at a university hospital based on acoustic measurements and noise mapping. Open Journal of Acoustics 2016; 6(4): 7185 .

[7] Marshall L. Architectural acoustics. $2^{\text {nd }}$ Edition, Academic Press, Oaks, USA. 2014.

[8] Srivastava V, Rajeev S. On the polymeric foam: modelling and properties. Journal of Materials Science 2014; 49(7): 2681-2692.

[9] Rajappan S, Bhaskaran P, Ravindran P. An insight into the composite materials for passive sound absorption. Journal of Applied Sciences 2017; 17: 339-356.

[10] Singla M, Chawla V. Mechanical properties of epoxy resin fly-ash composite. Journal of Minerals and Materials Characterization and Engineering 2010; 9(3): 184-199.

[11] Bratu M, Ropota I, Vasile O, Dumitrescu O, Muntean M. Sound-absorbing properties of composite materials reinforced with various wastes. Environmental Engineering and Management Journal 2011; 10(8): 1047-1051.

[12] Berardi U, Iannace G. Predicting the sound absorption of natural materials: best fit inverse laws for the acoustic impedance and propagation constant. Applied Acoustics 2017; 115: 131-138.

[13] Elena V, Natalia A, Leonard A, Alexander G. Fly ash cenospheres: composition, morphology, structure and helium permeability. World of Coal Ash Conference (WOCA), 9-12 ${ }^{\text {th }}$ May, 2011; Denver, CO, USA.

[14] Ward J. Annual coal ash production and use report. Published by the American Coal Ash Association (ACAA), 2015; Mississippi, USA.

[15] Arenas C, Leiva C, Luis F, Jose V. Development of acoustic barriers mainly composed of COcombustion bottom ash. World Coal Ash Conference, 9-12 $2^{\text {th }}$ May, 2011; Denver, CO, USA.

[16] Mamtaz H, Fouladi MH, Al-Atabi M, Narayana NS. Acoustic absorption of natural fiber composites. Journal of Engineering 2016; 1-11.

[17] Rizlan Z, Mamat O. Process parameters optimisation of silica sand nanoparticles using low speed ball milling method. Chinese Journal of Engineering, 2014; 8: 1-4.

[18] Subramani K, Rangaraj S, Rajendran V. Influence of ball milling on the particle size and antomacrobial property of tridax procumbens leaf nanoparticles. Journal of the Institution of Engineering and Technology, Nanotechnology, 2016; 11(1): 25-32.

[19] Jun CG, Yoon SK, Choi NJ. Application of fly ash as an absorbent for removal of air and water pollutants. Applied Sciences 2018; 8(7): 1116-1125.

[20] Jijun T, Zhou H, Yang Z, Zhang J. Properties of graphene oxide/epoxy resin composites. Journal of Nanoparticles 2014; 1-5. 
Sekunowo et al. / Eskişehir Technical Univ. J. of Sci. and Tech. A - Appl. Sci. and Eng. 21(4) - 2020

[21] Lee H, Pun M, Rammohan A, Tran L. An investigation of the sound absorption properties of flax/epoxy composites compared with glass/epoxy composites. Journal of Natural Fibers, 2017; 14(1): 71-77.

[22] Wambua P, Ivens J, Verpoest I. Natural fibres: Can they replace glass in fibre reinforced plastics? Composites Science and Technology, 2003; 63(9): 1259-1264.

[23] Yan L, Chouw N. Crashworthiness characteristics of flax fibre reinforced epoxy tubes for energy absorption application. Materials \& Design, 2013; 51: 629-640.

[24] Mahzan S, Zaidi AMA, Ghazali MI, Yahya MN, Ismail M. Investigation on sound absorption of rice-husk reinforced composite. Proceedings of MUCEET 2009 Malaysian Technical Universities Conference on Engineering and Technology, 20-22 June 2009; MS Garden, Kuantan, Pahang, Malaysia: pp. 9-22.

[25] Newman RB. Noise control for building: guidelines for acoustical problem solving. CertainTeed, 20 Moores Road, Malvern, PA19355, USA.

[26] Margem JI, Gomes VA, Margem FM, Ribeiro CG, Braga FO, Monteiro SN. Flexural behavior of epoxy matrix composites reinforced with malva fiber. Materials Research, 2015; 18: 114-120.

[27] Reddy MI, Kumar MA, Raju RB. Tensile and flexural properties of jute, pineapple leaf and glass fiber reinforced polymer matrix hybrid composites. Materials Today Proceeding, 2018; 1: 458462.

[28] Sinval AR, Cesar HZ, Radrigo VC, Demarco FF. Flexural and modulus of elasticity of different types of resin-based composites. Dental Materials 2007; 21(1): 16-21.

[29] Leiva C, Arenas C, Vilches LF, Alonso-Fariñas B, Rodriguez-Galán M. Development of fly-ash boards with thermal, acoustic and fire insulation properties. Waste Management 2015; 46: 298303.

[30] Gloria GO, Margem FM, Ribeiro CG, Moraes YM, Cruz RB, Silva FA, Monterio SN. Charpy impact tests of epoxy composites reinforced with giant bamboo fibers. Materials Research, 2015; 18: $178-184$.

[31] Younis SI, Oleiwi JK, Mohammed RA. Some mechanical properties of polymer matrix composites reinforced by nano silica particles and glass fibers. Engineering and Technology Journal, 2018; 36(12): 1283-1289.

[32] AL-Zubidi AB, AL-Hassani ES, Mohammed RA. Effect of nature materials powders on mechanical and physical properties of glass fiber / epoxy composite. Engineering and Technology Journal, 2015; 33(1): 175-197. 